\title{
ANATOMIA DA MADEIRA DE CALYCOPHYLLUM SPRUCEANUM (BENTH.) K. SCHUM. E CALYCOPHYLLUM SPRUCEANUM F. BRASILIENSIS K. SCHUM. ${ }^{1}$
}

\author{
TALITA BALDIN² JOSÉ NEWTON CARDOSO MARCHIORI ${ }^{3}$
}

\section{RESUMO}

As madeiras de Calycophyllum spruceanum e C. spruceanum f. brasilisensis são anatomicamente descritas e ilustradas com fotomicrografias. Ambas compartilham os seguintes caracteres: anéis de crescimento distintos; poros numerosos, em arranjo radial e de paredes espessas; porosidade difusa; placas de perfuração simples; pontoações intervasculares pequenas, ornamentadas; parênquima axial ausente; raios heterocelulares; e fibras libriformes septadas, de comprimento médio, com paredes delgadas a espessas. A estrutura anatômica da madeira inclina-se favoravelmente à proposição de K. Schumann e Mueller Argoviensis, que consideraram a forma brasiliensis como táxon infraespecífico de Calycophyllum spruceanum.

Palavras-chave: Anatomia da madeira, Calycophyllum spruceanum, Calycophyllum spruceanum f. brasiliensis, Ixoroideae, Rubiaceae.

\section{ABSTRACT}

[Wood anatomy of Calycophyllum spruceanum (Benth.) K. Schum. and Calycophyllum spruceanum f. brasiliensis K. Schum.].

The woods of Calycophyllum spruceanum and C. spruceanum f. brasiliensis are anatomically described and illustrated with photomicrographs. Both share the following features: distinct growth rings; diffuseporous wood, with numerous thick-walled vessels, in radial and diffuse arrangement; simple perforation plates; vestured intervessel pits; absent axial parenchyma; heterogeneous rays; and medium length libriform septate fibers, with thin to thick-walls. The wood anatomy leans in favor of K. Schumann and Mueller Argoviensis proposal of recognizing the brasiliensis form as an infraespecific taxon of Calycophyllum spruceanum.

Key words: Wood anatomy, Calycophyllum spruceanum, Calycophyllum spruceanum f. brasiliensis, Ixoroideae, Rubiaceae.

\section{INTRODUÇÃO}

Neotropical, o gênero Calycophyllum A. DC. insere-se, atualmente, na subfamília Ixoroideae (Rubiaceae) e distribui-se do México ao Brasil (Mendoza et al., 2004).

Devido às constantes atualizações na literatura botânica, bem como às recentes mudanças filogenéticas no Reino das Plantas, o número

1 Recebido em 04-06-2015 e aceito para publicação em 21-09-2014.

2 Engenheira Florestal, doutoranda do Programa de PósGraduação em Engenharia Florestal, Universidade Federal de Santa Maria. talita.baldin@ hotmail.com

3 Engenheiro Florestal, Professor Titular, Dr., Departamento de Ciências Florestais, Universidade Federal de Santa Maria. Bolsista de Produtividade em Pesquisa (CNPq-Brasil). marchiori@pq.cnpq.br de espécies de Calycophyllum é objeto de controvérsia. Delprete (1996) reconhece a existência de apenas dez espécies. No herbário do New York Botanical Garden (2014) constam nove espécies. De acordo com o International Plant Names Index (IPNI, 2014), os binômios são em número de 21 , entre espécies válidas e sinonímias.

O gênero Calycophyllum deve seu nome à conspícua sépala foliácea de suas flores, caráter que, entretanto, não é exclusividade desse grupo de Rubiaceae (Bacigalupo, 1968).

Árvores medianas a grandes, as espécies de Calycophyllum têm copa emergente no dossel, tronco comumente retilíneo e casca lisa, brilhante, de cor avermelhada ou marrom-escura e deiscência em tiras (Record \& Hess, 1949); a 
casca jovem, que se forma após esse desprendimento, geralmente é esverdeada (Mendoza et al., 2004).

Calycophyllum spruceanum (Benth.) K. Schum. é popularmente chamado de "pau-mulato" (Brasil), "capirona" (Peru) e "bayabochi" (Bolívia). O nome comum em português remete à cor escura da casca, que se descama em tiras. Trata-se de árvore moderadamente grande e de ampla dispersão ao longo do rio Amazonas, que habita, principalmente, solos argilosos férteis e inundáveis, inclusive no Peru, noroeste da Bolívia e Colômbia. Espécie heliófila e de rápido crescimento, apresenta incremento diamétrico anual de 4 a $6 \mathrm{~mm}$ (Bacigalupo, 1968).

Calycophyllum spruceanum é o único binômio do gênero com interesse comercial no Brasil. A madeira, de alta massa específica, tem cor marrom-escura e boa durabilidade natural, aspectos que a recomendam no mercado internacional, inclusive para fabricação de móveis (Record \& Hess, 1949).

Na Flora Brasiliensis, a família Rubiaceae foi trabalhada por K. Schumann e Mueller Argoviensis, constando 99 gêneros e 1043 espécies. Cabe salientar que os autores reconheceram as formas brasiliensis e peruviana de Calycophyllum spruceanum, distinguindo-as pela forma do fruto capsular: globoso, de ápice arredondado e com brácteas glabérrimas, na forma brasiliensis; e acuminado, com brácteas pilosas, na forma peruviana (Chiquieri et al., 2004). De acordo com o International Plant Names Index (IPNI, 2014), estas duas formas botânicas não são atualmente reconhecidas como válidas. É por este motivo, justamente, que o estudo anatômico do lenho, em exame independente, pode lançar novo enfoque à questão.

Face ao exposto, o presente trabalho busca investigar, sob o ponto de vista anatômico, a madeira de Calycophyllum spruceanum e $C$. spruceanum $\mathrm{f}$. brasiliensis, com vistas a contribuir ao conhecimento anatômico das Rubiáceas, e à definição do posicionamento taxonômico da referida forma botânica.

\section{MATERIAL E MÉTODOS}

No presente estudo foram analisadas quatro amostras de madeira de Calycophyllum spruceanum e uma de C. spruceanum $\mathrm{f}$. brasiliensis, recebidas do Jodrell Laboratory (Kew Gardens, Londres), do Instituto de Pesquisas Tecnológicas do estado de São Paulo (IPT) e da Black Forest Academy (BFA, Alemanha), constando, para as mesmas, os seguintes números de registros: KEW-22228, 22450; IPT- 294, 1309; BFA- 13196.

Para confecção de lâminas de cortes anatômicos, foram extraídos três corpos-de-prova de cada amostra $(3 \times 3 \times 3 \mathrm{~cm})$, devidamente orientados para a obtenção de cortes nos planos transversal (X), longitudinal radial (R) e longitudinal tangencial (T). Um quarto bloquinho foi também retirado, com vistas à maceração. A montagem das lâminas foi realizada no Laboratório de Anatomia da Madeira da Universidade Federal do Paraná, de acordo com a técnica padrão (Burger \& Richter, 1991). Para a dissociação do tecido lenhoso, usou-se o método de Franklin modificado (Kraus \& Arduin, 1997).

A descrição qualitativa do lenho baseou-se nas recomendações do IAWA Committee (1989), com exceção da percentagem dos distintos tecidos, da altura e largura de raios (inclusive de seu corpo e margens, em número de células), bem como da espessura da parede de fibras e vasos, aspectos não contemplados na referida norma. A determinação da fração dos tecidos foi obtida com um contador de células, segundo metodologia recomendada por Marchiori (1980).

Os caracteres anatômicos foram medidos em microscópio binocular Carl Zeiss, provido de ocular com escala graduada, no Laboratório de Anatomia da Madeira da Universidade Federal de Santa Maria. Nas características quantitativas, os números entre parênteses equivalem aos 
valores mínimos e máximos observados; o valor que acompanha a média é o desvio padrão. As fotomicrografias foram tomadas em microscópio Leica DM 1000, equipado com câmera digital Olympus Camedia CX-40, no Laboratório de Anatomia da Madeira da UFSM/ CESNORS. O processamento das imagens foi realizado com o auxílio do programa CorelDRAW, X7 (64 Bit).

\section{DESCRIÇÕES ANATÔMICAS}

\section{Calycophyllum spruceanum}

Anéis de crescimento: distintos, marcados por fibras radialmente estreitas no lenho tardio, assim como pelo frequente alargamento de raios na transição de anéis (Figura 1B).

Vasos: arredondados, tendentes a ovais (83 $\pm 13(40-125) \mu \mathrm{m})$, de paredes espessas (4 \pm 2 (1-8) $\mu \mathrm{m})$, e em número de $98 \pm 16$ (69-130) poros $/ \mathrm{mm}^{2}$, ocupando $29 \%$ do volume da madeira; em múltiplos radiais de 2-6 (54\%), solitários (40\%), menos comumente em racemos de 3-5 unidades (6\%). Vasos em frequente contato com células de raio. Porosidade difusa, uniforme (Figura 1A,B). Elementos vasculares de 589 \pm 225 (210-1013) $\mu \mathrm{m}$ de comprimento, com placas de perfuração simples, oblíquas. Apêndices, longos $(101 \pm 64(20-420) \mu \mathrm{m})$, em ambas, menos comumente em uma extremidade. Espessamentos helicoidais, estriações e tilos, não observados. Conteúdo, abundante. Pontoações intervasculares pequenas, arredondadas (5 \pm 1 (3-8) $\mu \mathrm{m})$, alternas, com abertura lenticular, horizontal, inclusa, ornamentada. Pontoações raio-vasculares, semelhantes, embora menores $(3 \pm 1(3-5) \mu \mathrm{m})$ do que as intervasculares.

Parênquima axial: ausente.

Raios: em número de $11 \pm 2$ (8-14) /mm, representando $24 \%$ do volume da madeira; heterogêneos e de dois tamanhos distintos, com células procumbentes, quadradas e eretas (Figura 1C). Raios fusionados, frequentes; raios agregados, ausentes. Os unisseriados, escassos
(12\%), com células quadradas no corpo central (1-8 fileiras) e 1 fileira de células eretas nas margens; de $279 \pm 110$ (110-620) $\mu \mathrm{m}$ de altura, com $4 \pm 2$ (1-5) células, e $14 \pm 4$ (5-25) $\mu \mathrm{m}$ de largura. Os multisseriados, em sua maioria tri e tetrasseriados (43 e 38\%, respectivamente), menos comumente bisseriados (4\%) e escassos (3\%) com 5 células de largura (Figura 1E); compostos de células procumbentes, na parte central (5-52), e 1-5 fileiras marginais de células quadradas e eretas; de $554 \pm 161$ (200-1230) $\mu \mathrm{m}$ de altura, com $22 \pm 8$ (7-54) células, e $39 \pm$ 15 (13-85) $\mu \mathrm{m}$ de largura. Células perfuradas de raio, frequentes entre as quadradas e eretas. Células envolventes, cristalíferas e latericuliformes, ausentes.

Fibras: libriformes, septadas, representando, aproximadamente, $47 \%$ do volume da madeira; com pontoações simples e em fenda vertical, restritas às faces radiais da parede (Figura $1 \mathrm{~F}$ ). Fibras de comprimento médio (1441 \pm 366 (7202400) $\mu \mathrm{m})$, e paredes delgadas a espessas ( $7 \pm$ 2(3-21) $\mu \mathrm{m})$. Espessamentos espiralados, fibras gelatinosas e traqueóides, ausentes.

Outros caracteres: cristais (areia cristalina) e depósitos, presentes nas células radiais (Figura 1D). Variantes cambiais, tubos laticíferos e taniníferos, canais intercelulares, células oleíferas, inclusões minerais, células mucilaginosas e estratificações, ausentes. Máculas medulares, presentes (Figura 1A).

\section{Calycophyllum spruceanum f. brasiliensis}

Anéis de crescimento: distintos, visualizados por fibras de menor diâmetro radial e paredes mais espessas ao final do lenho tardio, bem como por pequeno alargamento de raios na transição do anel (Figura 2B).

Vasos: muito numerosos (97 \pm 8 (82-109) poros $\left./ \mathrm{mm}^{2}\right)$, em arranjo radial, de seção arredondada, tendente a oval (71 $\pm 11(55-93) \mu \mathrm{m})$ e paredes espessas (5 $\pm 1(3-8) \mu \mathrm{m})$, perfazendo $23 \%$ do volume da madeira (Figura 2A, B). Vasos em porosidade difusa, uniforme, com frequentes contatos com células de raio; agrupa- 

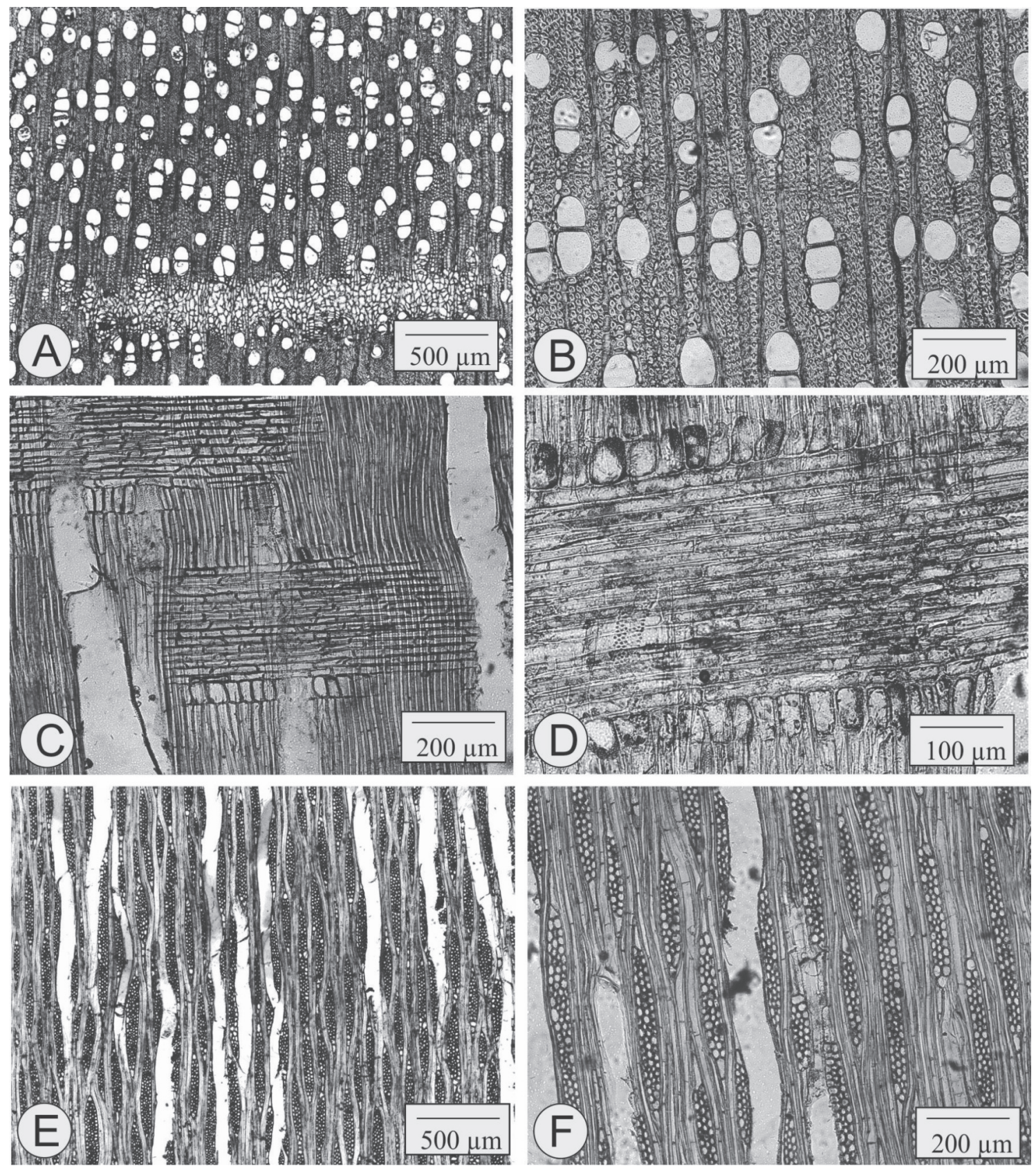

Figura 1 - Aspectos anatômicos do lenho de Calycophyllum spruceanum. A - Poros muito numerosos, solitários, em múltiplos radiais e em escassos racemos, com frequentes contatos com células de raio; mácula medular, presente (seção transversal). B - Mesma seção, em maior aumento, destacando anel de crescimento demarcado por fibras radialmente estreitas e pelo alargamento de raios; poros arredondados, tendentes a ovais. C - Raio heterogêneo, em seção longitudinal radial, com células procumbentes, ao centro, e margens de células quadradas e eretas. D - Seção longitudinal radial, em maior aumento, evidenciando areia cristalina e depósitos. E - Aspecto da seção longitudinal tangencial, evidenciando raios com 1-5 (ou mais) células de largura. F - Fibras libriformes, septadas, e raios uni e multisseriados (seção longitudinal tangencial). 
dos em múltiplos radiais de 2-6 (45\%), solitários $(50 \%)$ ou em escassos racemiformes $(5 \%)$ de 3-6 unidades (Figura 2A). Elementos vasculares de comprimento médio (649 \pm 170 $(270-900) \mu \mathrm{m})$. Placas de perfuração simples (Figura 2C), oblíquas. Apêndices longos (110 \pm 74 (30-290) $\mu \mathrm{m})$, em ambas ou em uma extremidade. Pontoações intervasculares pequenas, arredondadas ( $7 \pm 1(5-8) \mu \mathrm{m})$, alternas, com abertura lenticular, horizontal, inclusa, ornamentada (Figura 2F). Pontoações raio-vasculares, semelhantes, mas menores $(4 \pm 1(3-5) \mu \mathrm{m})$ do que as intervasculares. Tilos, espessamentos helicoidais, estriações e depósitos, ausentes.

Parênquima axial: ausente.

Raios: em número de $12 \pm 1$ (10-15) /mm, heterogêneos e de dois tamanhos distintos, representando $31 \%$ do volume da madeira. Os unisseriados, escassos (8\%), de células quadradas e eretas; de $303 \pm 126$ (110-590) $\mu \mathrm{m}$ de altura, com $4 \pm 2$ (2-9) células e $15 \pm 3$ (10-20) $\mu \mathrm{m}$ de largura. Os multisseriados (Figura 2E), em sua maioria tetrasseriados $(62 \%)$, menos comumente trisseriados (22\%), com poucos 5seriados (7\%), compostos de células procumbentes (6-21), no corpo central, e 1-3 fileiras marginais de células quadradas e eretas; de $467 \pm 91$ (300-660) $\mu \mathrm{m}$ de altura, com $17 \pm 4$ (9-24) células, e $30 \pm 9$ (30-75) $\mu \mathrm{m}$ de largura (Figura 2C). Raios fusionados, presentes. Raios agregados, ausentes. Células perfuradas, presentes; células latericuliformes, envolventes e oleíferas, ausentes.

Fibras: libriformes, septadas (Figura 2E, F), de comprimento médio (1371 \pm 249 (850-1780) $\mu \mathrm{m})$ e paredes delgadas a espessas $(6 \pm 2(3-15)$ $\mu \mathrm{m})$, ocupando $46 \%$ do volume da madeira. Pontoações simples, em fenda vertical, nas faces radiais da parede. Fibras gelatinosas, espessamentos helicoidais e traqueóides, ausentes.

Outros caracteres: cristais, em forma de areia (microcristais), e depósitos, presentes em células de raio (Figura 2D). Canais celulares, estru- tura estratificada, sílica, floema incluso, células oleíferas, células mucilaginosas e máculas medulares, ausentes.

\section{ANÁLISE ANATÔMICA}

O conjunto de caracteres anatômicos verificado no presente estudo está de acordo com o padrão descrito por Record \& Hess (1949), Koek-Noorman (1972) e Metcalfe \& Chalk (1972) para a estrutura "tipo II" de Rubiaceae: poros predominantemente em múltiplos radiais; parênquima axial ausente; raios largos (2-4 células ou mais), com células quadradas e eretas em estreitas margens; e fibras septadas com pontoações simples.

Sob o ponto de vista taxonômico, tanto Calycophyllum spruceanum como C. spruceanum f. brasiliensis não atendem aos padrões anatômicos referidos por Koek-Noorman (1972) e Jansen et al. (1997, 1999) para a subfamília Ixoroideae: vasos solitários, menos comumente em curtos múltiplos radiais; fibrotraqueóides; e parênquima axial difuso, difuso-em-agregados ou em pequenas linhas marginais.

Tanto Calycophyllum spruceanum f. brasiliensis como C. spruceanum compartilham grande número de caracteres anatômicos em comum: porosidade difusa; poros numerosos e em arranjo radial; vasos de paredes espessas, com placas de perfurações simples e apêndices longos; pontoações intervasculares pequenas, ornamentadas; parênquima axial ausente; raios heterocelulares; e fibras libriformes septadas, de comprimento médio, com paredes delgadas a espessas. A grande semelhança anatômica entre os dois materiais reforça o posicionamento infraespecífico da referida forma botânica.

Apesar do numeroso conjunto de detalhes anatômicos em comum, os caracteres quantitativos relacionados na Tabela 1, permitem a segregação de ambos os materiais. 

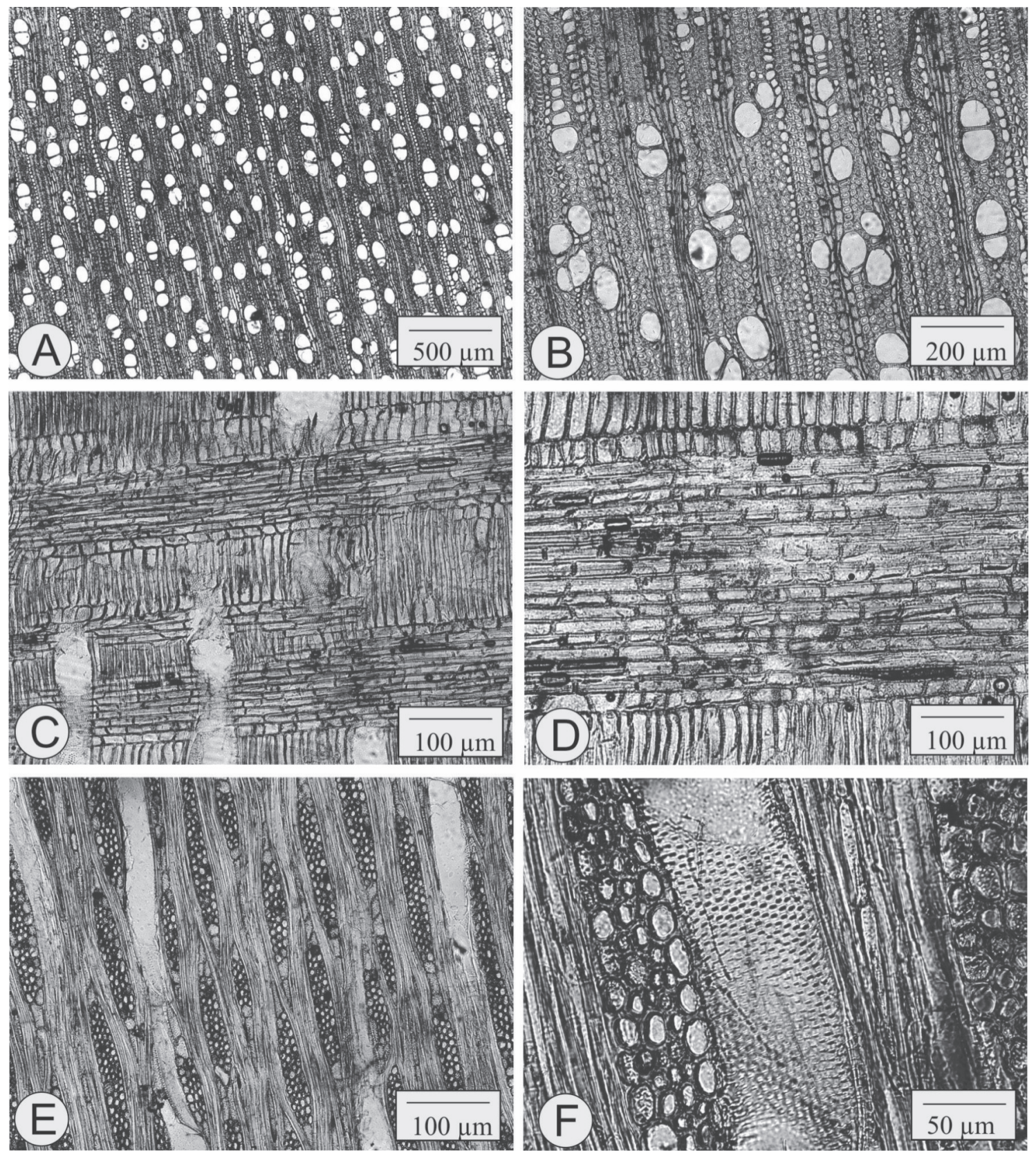

Figura 2 - Aspectos anatômicos do lenho de Calycophyllum spruceanum f. brasiliensis. A - Porosidade difusa, poros muito numerosos, solitários, em múltiplos radiais e escassos racemos, com frequentes contatos com células de raio (seção transversal). B - Mesma seção, em maior aumento, destacando um limite do anel de crescimento e poros de seção arredondada, tendente a oval. C - Raio heterogêneo, em seção longitudinal radial, com células procumbentes, ao centro, e células quadradas e eretas, nas margens. D - Seção longitudinal radial, em maior aumento, salientando areia cristalina e depósitos. E - Aspecto da seção longitudinal tangencial, com raios predominantemente tetrasseridados e fibras libriformes septadas. F - Mesma seção, em maior aumento, evidenciando pontoações intervasculares pequenas e ornamentadas, e fibras septadas. 
Tabela 1: Caracteres diferenciais entre Calycophyllum spruceanum e C. spruceanum $\mathrm{f}$. brasiliensis

\begin{tabular}{l|cc}
\hline \multicolumn{1}{c|}{ Caracteres anatômicos } & C.s & C.s. f. $b$ \\
\hline Poros geralmente em contato com células de raio & 0 & 1 \\
Raios multisseriados, em sua maioria trisseriados & 1 & 0 \\
Raios multisseriados, geralmente tetrasseriados & 0 & 1 \\
Raios multisseriados com 14-17 células de altura & 0 & 1 \\
Raios multisseriados com mais de 17 células de altura & 1 & 0 \\
Raios multisseriados com 26-33 $\mu \mathrm{m}$ de largura & 0 & 1 \\
Raios multisseriados com mais de $33 \mu \mathrm{m}$ de largura & 1 & 0 \\
\hline
\end{tabular}

Onde: Caráter anatômico presente (1). Caráter anatômico ausente (0). C.s (Calycophyllum spruceanum), C. s. f. b (Calycophyllum spruceanum f. brasiliensis)

As principais diferenças observadas residem no parênquima radial. A largura dos raios também varia sensivelmente, auxiliando na distinção dos materiais. Em Calycophyllum spruceanum $\mathrm{f}$. brasiliensis ocorrem raios largos, predominantemente com quatro (não raro 5 ou mais) células. Em C. spruceanum, ao contrário, predominam os trisseriados.

A largura de raios em número de células parece ter grande variação em Rubiaceae. Metcalfe \& Chalk (1972) estimam a ocorrência de raios estreitos, com 2-3 células de largura, em cerca de $70 \%$ dos gêneros; por sua vez, raios largos, com mais de quatro células, são referidos para 42 gêneros da família. A variação na largura de raios também se verifica na subfamília Ixoroideae: de acordo com Record \& Hess (1949), o caráter "raios unisseriados", com escassos bisseriados, é citado para Alibertia e Bertiera; raios largos, com 6 ou mais células, são mencionados para Chimarrhis Jacq.,
Warscewiczia Klotzsch, Capirona Spruce e Hamelia Jacq.

A altura dos raios, do mesmo modo, mostrase importante na separação de espécies. Os multisseriados, com maiores valores médios, foram encontrados em C. spruceanum $(554 \mu \mathrm{m})$. No caso dos unisseriados, no contrário, as maiores dimensões foram encontradas em $C$. spruceanum $\mathrm{f}$. brasiliensis $(303 \mu \mathrm{m})$.

Como peculiaridade, ressalva-se em Calycophyllum spruceanum o frequente contato de poros com células de parênquima radial. A característica pode servir de subsídio para a distinção, visto não ser reportada para o conjunto das Rubiaceae. Maiores considerações a respeito, todavia, ficam limitadas pela ausência de citações a respeito, na literatura.

A anatomia da madeira, em suma, inclina-se favoravelmente ao reconhecimento da forma brasiliensis como táxon infraespecífico, estabelecido por K. Schumann e Mueller Argoviensis na Flora brasiliensis. 


\section{REFERÊNCIAS BIBLIOGRÁFICAS}

BACIGALUPO, M.N. Sinopsis preliminar del género Calycophyllum (Rubiaceae). Darwiniana, v. 14, n. 4, p. 639-653, 1968.

BURGER, L.M.; RICHTER, H.G. Anatomia da Madeira. São Paulo: Ed. Nobel, 1991. 154 p.

CHIQUIERI, A.; DI MAIO, F.R.; PEIXOTO, A.L. A distribuição geográfica da família Rubiaceae Juss. na Flora Brasiliensis de Martius. Rodriguésia, v. 55, n. 84, p. 47-57, 2004.

DELPRETE, P.G. Evaluation of the tribes Chiococceae, Condamineeae and Catesbaeeae (Rubiaceae), based on morphological characters. Opera Botanica Belgica, v. 7, p. 165-192, 1996.

IAWA COMMITTEE. IAWA list of microscopic features for hardwood identificacion. IAWA Bulletin, v. 10, n. 3, p. 218-359, 1989.

JANSEN, S.E.; ROBBRECHT, H.; BEECKMAN, $\mathrm{H}$; SMETS, E. Comparative wood anatomy of African Coffeeae (Rubiaceae-Ixoroideae). Belg. J. Bot. n. 130, p. 47-58. 1997.

JANSEN, S.; BLOCK, P.; BEECKMAN, H.; SMETS, E. Systematic wood anatomy of the Pavetteae (Rubiaceae-Ixoroideae). Syst. Geogr, v. 68, p. 113-133. 1999.
KOEK-NOORMAN, J. The wood anatomy of Gardeniae, Ixoreae and Mussaendeae (Rubiaceae). Acta Botanica Neerlandica, v. 21, n. 3, p. 301-320, 1972.

KRAUS, J.E.; ARDUIN, M. Manual básico de métodos em morfologia vegetal. Rio de Janeiro: EDUR, 1997. 198 p.

MARCHIORI, J.N.C. Estudo anatômico do xilema secundário de algumas espécies dos gêneros Acacia e Mimosa, nativas no estado do Rio Grande do Sul. 1980. 186 f. Dissertação (Mestrado em Engenharia Florestal Universidade Federal do Paraná), Curitiba, 1980.

MENDOZA, H.; RAMÍREZ, B.; JIMÉNEZ, L. C. Rubiaceae de Colombia: guia ilustrada de géneros. Instituto de Investigación de Recursos Biológicos Alexander von Humboldt. Bogotá, Colombia. 2004. 351 p.

METCALFE, C.R.; CHALK, L. Anatomy of the Dicotyledons. Oxford: Clarendon Press, 1972. $1500 \mathrm{p}$.

RECORD, S.J.; HESS, R.W. Timbers of The New World. New Haven: Yale University Press, 1949. $640 \mathrm{p}$.

THE INTERNATIONAL PLANT NAMES INDEX (2014). Published on the Internet. http:// www.ipni.org [accessed 03 jan 2014] 